Royal Festival Hall on May 30, presided over by the Lord High Chancellor, the Right Hon. the Viscount Kilmuir ; on May 31, a Government reception was held at Lancaster House under the auspices of the Board of Trade, which wes also attended by Prince Philip; on June 2 the delegates attended a gala performance of "The Barber of Seville" at the Royal Opera House; and on June 3 the closing banquet was held in the Great Hall of the Royal Courts of Justice (by permission of the Lord Chancellor and the Minister of Works), followed by a ball in the Halls of the Middle and Inner Temples (by pormission of the Benchers of the Middle Temple and Inner Temple).

In consequence of the earnest representations of the German Group, it was agreed that the next Congress of the International Association for the Protection of Industrial Property be held in Berlin in 1963. The Japanese Group also mado strong representations that the Congress following tho Berlin one be held in Tokyo in 1966, especially as the
Association has never yet met in Asia. In view of the decision to hold the next Congress in Berlin, an invitation was sent to Peter von Siemens, of Werner von Siemens, Erlangen, to succeed Sir John HanburyWilliams as piesident.

'The permanent officers of the International Association are: Secretary-General, Eugène Blum ; Assistant Secretary-General, Dr. Rudolf Blum, of Zurich, the headquarters of the Association; Reporter General, M. Paul Mathely (Paris); and Treasurer General, M. Jaques Bede (Brussels). The president of the British Group is Mr. G. W. Tookey, Q.C., the joint secretaries, Mr. Michael Hesketh-Prichard (chartered patent agent) and Mr. Martin H. Lowry (solicitor), and the treasurer Mr. L. A. Ellwood (solicitor). The president of the German Group, which will be responsible generally for the organization and running of the next Congress, is Herr H. G. Heine (patent agent), and the secretary, Herr Moser von Filseck (advocate).

H. C. MILlen

\title{
PARASITES AS ENEMIES AND ALLIES
}

$\mathrm{T}$ HE Spring Meeting of the Parasitology Group of the Institute of Biology was held during April 6-8 in the new buildings of the Liverpool School of Tropical Medicine, by kind arrangement with Prof. W. E. Kershaw. This was the second annual meeting of its kind, and was attended by about a hundred biologists with widely differing interests in parasitology.

Twenty offered papers were concerned with a variety of disciplines and of animal parasites, ranging from studies on the biology of the tapeworm larva, Cysticercus bovis (P. H. Silverman), to mitochondrial enzymes in relation to malaria (B. G. Maegraith) and a mathematical analysis of populations of helminths in wild and domesticated animals (H. D. Crofton). The invited speaker, Prof. T. H. Davey, surveyed the role and status of parasites in his discourse on "Parasites as Enemies and Allies".

In the rapidly developing field of physiology of parasites, R. L. Muller presented his experiments on glycogen metabolism in Faplometra cylindracea and showed this fluke to ke an obligate aerobe-a nice correlation with its habitat in the lung of the frog. Investigations into the growth patterns of certain tapeworms, undertaken by C. A. Hopkins, revealed that during growth the plerocercoid larva doubles its weight every $24 \mathrm{hr}$., and that it becomes infective kefore reaching its maximum size. Under the stimulus of transmission to the defnitive host, exponential growth is resumed until maturation of the worm. Hopkins suggested thet et meturation a growth-inhibiting substance is produced which, because of linear growth and the lack of a circulatory system, dces not affect the anterior region of the worm. The proteolytic activity of extracts prepared from Entamceba histolytica and the optimum conditions for proteolysis were reported by R. A. Neal.

Histochemical studies included the distribution of nucleic acids in normal and in akinetoplastic strains of Trypanosoma eransi by J. R. Baker. D. L. Lee showed that the ovijector of Thclastoma bi lhcesi, a nematode inhabiting the hind-gut of the cockroach, secretes a mucoprotein responsible for the sticky covering of the eggs. Certain aspects of the behaviour of parasites were treated by $\mathbf{F}$. Hawking and M. J. Worms, who descriked responses of microfilaria counts of Monnigofilaria setariosa to external stimuli applied to the host, the mongoose, and who discussed reasons for the periodic migrations of microfilariæ into the peripheral blood.

A knowledge of the life-cycle of a parasite is fundamentally important to epidemiological studies of parasitic diseases, and work by T. E. Gibson on the development of eggs and larvæ of two species of sheep nematode, Nematodirus battus and N. filicollis, and on pasture population densities has allowed grazing management methods to be devised which enable complete control of the disease. The density of parasite populations is also important in the case of ducks harbouring the acanthocephalan Polymorphus minutus, which under certain conditions can cause serious losses, and H. B. N. Hynes gave an account of the way in which the parasite spreads by means of its intermediate host, Gammarus spp., from an infected flock penned on to a small stream.

An example of how a population of parasites may serve as an indicator of different zoogeographical populations of host was illustrated by Z. Kabata. Whiting inhabiting the North Sea to the north of the Dogger Bank harbour abundant Ceratomyxa in the gall bladder, whereas fish to the south are infected with Myxidium. There are also differences in the myxosporidian fauna of these fish from the Faeroes and of the haddock from these areas.

Parasitic infections may evoke immune reactions in the host, and this hest-reaction can be utilized to test for the presence of the parasite. R. J. Terry, D. Poynter and P. H. Silverman reviewed and appraised the value of various hæmatological and serological techniques employed in diagnostic tests. Further uses of host-reaction in detecting the presence of a parasite were reported by S. F. M. Davies and L. P. Joyner, who found that in chicks with a sub-lethal 
infection of the coccidian Eimeria tenclla, the messure. ments of the resultant anæmia provided a more sensitive means of detecting the parasite than do observations on the growth-rate of the chicks. In $E$. necatrix infections, however, there is a marked reduction in the growth-rate accompanied by only mild anæmia and the infections may thus be readily distinguished.

A host animal may show resistance to infestation by parasites, and J. F. Michel showed that resistance of the rabbit to the nematode, Trichostrongylus retortaeformis, may be manifested by the elimination of the adult worms, by arrest of development of the worms at the third larval stage or by preventing a new infestation from becoming established. The spontaneous elimination of parasites from the host known as self-cure also occurs in sheep infested with the nematode Haemonchus contortus. E. J. Soulsby investigated the serological reactions which take place at self-cure using complement fixation, hæmagglutination and Ochterlony agar diffusion precipitin techniques. The evidence indicates that at this time there is a marked immunological response and that the main antigenic stimulation is from substances released by larvæ undergoing the third moult.

The susceptibility of a host to infestation may be influenced by the presence of other parasites already established in the host, and the nature of the inter action between such intercurrent infestations was studied by J. E. D. Keeling in rats experimentally infested with Nippostrongylus muris and Strongyloides ratti and mice with Aspicularis tetraptera and Trichuris muris. The susceptibility of plant hosts to attack by animal parasites is different from that of an animal host, and differences between varieties of chrysanthemum in susceptibility to attack by eelworms were discussed by $H$. R. Wallace. The kehaviour of eelworms on the outside of the plant, the invasion of the leaves through the stomata and movement of the worms within the leaf were described. The evidence supports the theory that varietal variation in susceptibility is related to hypersensitivity of the leaf tissues to eelworm invasion.

The degree of host-specificity shown by a parasite may be important in the epidemiology of human disease, as in the case of a pathogen harboured by both man and his domestic animals. F. E. G. Cox posed the question, "Is Balantidium coli a zoonosis?" and presented data suggesting that this protozoan normally found in pigs is not, contrary to common belief, easily acquired by man except possibly in certain nutritionally deficient states. Another group of protozoans, the 'Limax' Amobae, have frequently been reported as parasites of both invertebrates and vertebrates, including man, and they are also abundant in the soil. Although these animals are similar morphologically they show great differences in their physiology and micro-anatomy and these differences are reflected in the ecology of the individual species. $K$. Vickerman submitted evidence that some of these 'Limax' Amobae are f£cultative pॄrasites closely related to soil-occurring forms, whereas others are obligate parasites more closely resembling the Endamoebidae.

A group of short papers and demonstrations described the work in progress at the Liverpool School of Tropical Medicine, and these together with three other laboratory demonstrations concluded the meeting. The proceedings of this meeting will not be published in full.
J. MAHON

\section{GLASSHOUSE CROPS RESEARCH INSTITUTE}

$\mathrm{T}$ HE Glasshouse Crops Research Institute, Littlehampton, Sussex, held its annual open day on May 17, more than four hundred visitors attending. The laboratories were open for inspection during the morning, and many visiting research workers and growers availed themselves of this opportunity to see the work in progress and to discuss aspects of it with the Institute's scientific staff. After lunch, the director, Mr. F. W. Toovey, gave a brief report to the issembled guests and visitors on the development of the Institute over the past year and on future plans, and directed sttention to some lines of work of particular interest and importance. During the afternoon a number of special demonstrations were wrranged in the experimental glasshouses and mushroom sheds.

In the tomato-breeding programme undertaken by Mr. L. A. Darby, the introduction of the even-ripening character of the 'Stonor' varieties into two wellknown stendard varieties, 'Potentate' and 'Ailsa Craig', was shown. The object of this is to eliminate the ripening disorder commonly known as 'greenback'. A parallel breeding programme has produced plants which have the compact habit of 'Baby Lea' but with the truss, fruit size and shape, and the freedom from 'greenback' of 'Moneymaker', the best-known of the 'Stonor' varieties. The new types hఓve yet to be tested for yielding ability, but it is hoped they will prove valuable to the grower as a means of producing better quality fruit.

The main variety trials were concerned with the further evaluation of selections descended from hybrids with the compact-habit (short internode) 'Baby Lea' variety, and include some which have attracted a good deal of interest among growers. Some of this material is being subjected to wide screening on growers' holdings and experiment stations this year.

Of interest in connexion with the tomato-breeding programme and other work at the Institute was a demonstration by the statistician (Mr. D. Cooke) of the results of a survey carried out in 1959 of the varieties of tomato grown commercially. From a 10 per cent sample of growers seventy distinct varieties were recorded, the four most commonly grown, according to total acreage, being 'Moneymaker', which occupied 32 per cent of the 2,067 acres estimated to have been grown in Great Britain in 1959, 'Potentate' (17 per cent), 'Ware Cross' (15 per cent) and 'Ailsa Craig' (6 per cent). Within this general pattern, however, there were marked differences according to district and time of planting.

The Chemistry Department, under Dr. G. W. Winsor, demonstrated some espects of its work on plant nutrition, composition and biochemistry. The nutrition trials now cover the tomato, carnation, 